\title{
ORIGINAL
}

\section{Retinoic acid and dexamethasone induce differentiation and maturation of somatotroph cells at different stages in vitro}

\author{
Yu Cheng ${ }^{1) *}$, Ying Xiang ${ }^{2) *}$, Youzhi Lin ${ }^{1)}$, Songbin $\mathrm{Fu}^{3)}$, Wenzhi Jia' ${ }^{1)}$, Guanghui Zhang1), Wenming $\mathrm{Lv}^{1)}$, \\ Shan $\mathrm{Mi}^{1)}$ and Qinghai Zhao ${ }^{1)}$ \\ 1) The Department of Neurological Surgery, First Affiliated Hospital, Harbin Medical University, Harbin 150001, P.R.China \\ 2) The Department of Endocrinology, Second Affiliated Hospital Harbin Medical University, Harbin 150086, P.R.China \\ 3) The Department of Medical Genetics, Harbin Medical University, P.R.China
}

\begin{abstract}
The purpose of this study was to investigate the role of retinoic acid (RA) and/or dexamethasone and growth hormone releasing hormone $(\mathrm{GHRH})$ in the induction of somatotroph cell differentiation. Immunohistochemistry, radioimmunoassay, 3-(4,5-dimethylthiazol -1,2-y1)-2,5-diphenyltetrazolium bromide assay, and immune electron microscopy were employed to determine the effect of incubation with these constituents on the differentiation into somatotrophs of cells isolated from the rat embryonic pituitary gland. RA administration increased the proportion of growth hormone $(\mathrm{GH})$ positive somatotroph cells and GH secretion in embryonic pituitary cells $(P<0.01)$. After 4 days of incubation with RA, additional administration of dexamethasone further increased the proportion of somatotroph cells and GH secretion $(P<0.01)$, and increased the number of secretory granules in the somatotroph cells. Addition of GHRH alone had no such effect $(P>0.05)$. However, addition of GHRH to treatment with RA plus dexamethasone significantly increased both the proportion of somatotroph cells and the secretion of GH compared to treatment with RA or dexamethasone alone or RA plus dexamethasone $(P<0.01)$. RA promoted the early differentiation of somatotroph cells, dexamethasone promoted the differentiation and maturation of somatotroph cells and in addition, RA, dexamethasone and GHRH together exerted synergistic effects that markedly promoted somatotroph cell differentiation, maturation and GH secretion.
\end{abstract}

Key words: Retinoic acid, Dexamethasone, Growth hormone releasing hormone, Somatotroph cell differentiation, Embryonic pituitary cells

DURING the development of the adenohypophysis, the differentiation of somatotroph cells requires the regulation of numerous endogenous and exogenous signals [1]. The steps leading to the differentiation of these GH cells are still not completely understood. Differentiation of GH cells can be divided into two stages: an early stage, in which stem cells or progenitor cells differentiate into early GH cells, and a late stage, in which the early GH cells further differentiate into mature, functional, GH-secreting cells [2]. In investigating the second stage of differentiation, many studies have focussed on the role of glucocorticoids, and

Received Oct. 21, 2010; Accepted Jan. 11, 2011 as K10E-315 Released online in J-STAGE as advance publication Feb. 22, 2011

Correspondence to: Yu Cheng, Ph.D., Department of Neurological Surgery, First Affiliated Hospital, Harbin Medical University\#23 Postal street, Nan Gang District, Harbin 150001, P.R.China.

E-mail: ccyy30@126.com

*These authors contribute equally to this work. their results show that glucocorticoids induce second stage differentiation and maturation of GH cells. But the role of glucocorticoids in the early differentiation of GH cells is still unclear.

Retinoic acid (RA) promotes the differentiation of numerous types of cells during vertebrate embryogenesis [3]. Some reports indicate that RA plays an important role in the early differentiation of GH cells $[4,5]$. When the RA synthesizing enzyme, type 2 retinal dehydrogenase, is present, RA increases the mRNA expression of pituitary-specific transcription factor (Pit-1) and induces GH cell differentiation [4, 6]. But at present, few studies have been conducted in primary cell culture to investigate the role of RA in the early differentiation of GH cells.

In the present study, rat embryonic pituitary cells were obtained and grown in order to provide a model to mimic differentiation of these cells at different stages of embryogenesis. The respective roles of RA, glu- 
cocorticoids and growth hormone releasing hormone (GHRH) in the differentiation of GH cells were evaluated. Our results may provide an optimal protocol for in vitro induction of GH cell differentiation and an experimental basis to guide clinical research into cell sources and protocols for transplantation of somatotrophs in patients with GH deficiency.

\section{Materials and Methods}

\section{Animal and agents}

Sprague-Dawley (SD) rats were purchased from the Animal Center of Harbin Medical University (License NO: SCXK [Jilin] 2003-0001). Dulbecco's Modified Eagle Medium (DMEM, Gibco/Invitrogen, Carlsbad, CA, USA), all-trans retinoic acid, dexamethasone, GHRH, rabbit anti-rat GH polyclonal antibodies (Sigma, St. Louis, MO, USA), MTT (3-(4,5-dimethylthiazol-2-yl)-2,5-diphenyltetrazolium bromide, Huashan Hospital, Shanghai P.R. China), radioimmunoassay kits (Institute of Radioimmunoassay of East Asia, Beijing, P.R. China), XTS2022 stereomicroscope (Beijing Tech Instrument Co., Ltd. Beijing, P.R. China), and JEM 1220 transmission electron microscope (Electronics Co. Tokyo, Japan) were used in the present study.

\section{Isolation of rat embryonic pituitary cells}

Male rats and female rats were fed in the same cage, and sperm smearing was performed on the second day. Pregnancy of rats was determined based on the sign of mucus plug and the date to find the mucus plug was regarded as embryonic day 0 (E0). Pregnant rats were sacrificed at E13 and the fetal rats obtained under aseptic conditions. The pituitary was separated under a stereomicroscope and a single cell suspension was prepared and cultured as previously reported $[7,8]$. Briefly, the isolated pituitary was rinsed with DMEM three times and then cut into small pieces and transferred into DMEM with $0.25 \%$ trypsin, $100 \mu \mathrm{g} /$ $\mathrm{mL}$ streptomycin and $100 \mathrm{U} / \mathrm{mL}$ penicillin, and cultured at $37^{\circ} \mathrm{C}$ with $5 \% \mathrm{CO}_{2}$ for 30 minutes. Digestion was stopped by adding $10 \%$ fetal bovine serum. The cells were rinsed twice with $10 \mathrm{~mL}$ DMEM and centrifuged at $1000 \mathrm{rpm}$ for 10 minutes. Finally, the cells were re-suspended in DMEM by gently pipetting them up and down several times. The cell suspension was put through a copper 200-mesh strainer, and the cell number counted with a haemocytometer. Fifty to 100 pituitaries were used for a single experiment. About 1 to $5 \times 10^{5}$ cells were isolated per pituitary. Trypan blue staining and cell counting were performed to make sure that the survival rate at the time of cell separation was greater than $90 \%$.

\section{Cell culture}

Generally, the rat E13 embryonic pituitary cells were cultured in basic medium only for 6 days as controls. In the RA treated groups, the cells were cultured in basic medium with RA for 4 days first followed by the adding of different factors and cultured for another 2 days before different detection.

For determination of RA ability to induce differentiation, after a 45 min incubation, RA in different final concentrations $\left(10^{-8} \mathrm{~mol} / \mathrm{L}, 10^{-7} \mathrm{~mol} / \mathrm{L}\right.$ and $\left.10^{-6} \mathrm{~mol} / \mathrm{L}\right)$ was added in DMEM supplemented with glutamine, penicillin and streptomycin at a final volume of $2 \mathrm{~mL} /$ well. The medium was refreshed with fresh medium with the adding of RA every $48 \mathrm{~h}$. Supernatant was obtained at days 2,4 , and 6 , and stored at $-80^{\circ}$ until use. The GH level in the supernatant was determined by radioimmunoassay.

For the detection of GH positive cells, poly-lysinecovered coverslips were independently placed in 12-well plates, and cells were seeded at a density of $2 \times 10^{5} / \mathrm{mL}$ (100 $\mu \mathrm{L} /$ well). Coverslips obtained from the plates were fixed in $4 \%$ paraformaldehyde for $20 \mathrm{~min}$, and immunohistochemistry was performed to detect GH positive cells and determine their proportion.

To investigate the effect of RA on the proliferation of embryonic pituitary cells, a pituitary cell suspension was prepared and divided into the following three groups: Group 1, medium alone; Group 2, $10^{-6} \mathrm{~mol} / \mathrm{L}$ RA; Group 3, $10^{-6} \mathrm{~mol} / \mathrm{L}$ basic fibroblast growth factor (bFGF). The 5000 cells were inoculated into each well before the treatment. After 6 days of incubation, the MTT assay was performed to detect the proportion of viable cells.

For comparison of the effects of RA, dexamethasone, and GHRH, dexamethasone (50 nmol/L), and/ or GHRH $\left(10^{-7} \mathrm{~mol} / \mathrm{L}\right)$ on cell differentiation, the cells were divided into 5 groups: Group 1 contained basic medium alone; Group 2 cells were treated with $10^{-6}$ $\mathrm{mol} / \mathrm{L}$ RA for 6 days. Group 3 cells were treated with $10^{-6} \mathrm{~mol} / \mathrm{L}$ RA for 4 days, then additional treatment with dexamethasone (50 nmol/L) for another 2 days. Group 4 were treated with $10^{-6} \mathrm{~mol} / \mathrm{L}$ RA for 4 days, then additional treatment with GHRH $\left(10^{-7} \mathrm{~mol} / \mathrm{L}\right)$ for 
another 2 days. Group 5 cells were incubated with RA $\left(10^{-6} \mathrm{~mol} / \mathrm{L}\right)$ for 4 days, then with GHRH $\left(10^{-7} \mathrm{~mol} / \mathrm{L}\right)$ plus dexamethasone $(50 \mathrm{nmol} / \mathrm{L})$ for another 2 days. Cells were harvested when the cell number in each group was at least $1 \times 10^{7}$ cells. These cells were then fixed in $1 \%$ paraformaldehyde plus $0.05 \%$ glutaraldehyde for $4 \mathrm{~h}$ and examined by immune electron microscopy. The supernatante were also collected and stored at $-80^{\circ}$ until use.

\section{Immunohistochemistry}

Immunohistochemistry was performed with a DAB staining kit (Boster Biological Technology, Ltd. China). The primary antibody was rabbit anti-rat GH polyclonal antibody (1:200; Sigma, USA) and replaced with 0.01 $\mathrm{mol} / \mathrm{L}$ PBS in the negative control. The secondary antibody was goat anti-rabbit IgG (Boster Biological Technology, Ltd. China). Four fields were randomly selected from each section (12 fields from 3 sections; $\times 20$ ). The cells with orange staining were regarded as $\mathrm{GH}-$ positive cells and the proportion of positive cells was determined.

\section{Detection of cell viability by MTT assay}

Cells in the logarithmic growth phase were obtained and seeded into 96-well plate (5000 cells/well), and each experiment was performed in octuplicate. The grouping was based on the experiment design, and medium alone $(100 \mu \mathrm{L})$ was included in the blank control. The supernatant was removed $4 \mathrm{~h}$ before detection and $100 \mu \mathrm{L}$ of $0.5 \mathrm{mg} / \mathrm{mL}$ MTT were added to each well followed by incubation for $4 \mathrm{~h}$. MTT was not added to the blank control. Then, the supernatant was removed and $200 \mu \mathrm{L}$ of DMSO were added to each well. When the crystalline solid resolved, the absorbance was determined at $490 \mathrm{~nm}$ with a microplate reader. This recorded the relative amount of live cells based on optical density measurements. We did not count actual cell number after treatment.

\section{Radioimmunoassay}

Radioimmunoassay was performed according to the manufacturer's instructions. There were 6 samples in each assay. The sensitivity was less than $0.05 \mathrm{ng} / \mathrm{mL}$. Measurement of radioactivity was performed with a $\gamma$ counter $\left({ }^{125} \mathrm{I}-\mathrm{GH}\right)$. The reagents were mixed, followed by centrifugation at $3500 \mathrm{rpm} / \mathrm{min}$ for $15 \mathrm{~min}$. The supernatant was carefully removed, and the radioactivity of the sediment was detected. A regression equa- tion was established with $\mathrm{B} / \mathrm{B}_{0} \sim \lg \mathrm{X}$ and the concentrations of samples were determined by the following equation:

$$
B_{1} / B_{0}(\%)=\frac{B(c p m)-N S B(c p m)}{B_{0}(c p m)-N S B(c p m)} \times 100 \%
$$

\section{Immune electron microscopy}

The cells were embedded followed by immunohistochemistry. The primary antibody was rabbit anti-rat polyclonal antibody (1:25, Sigma-Aldrich, St. Louis, MO, USA) and the diameter of SPA-colloidal gold (1:10, Boster Bio-Engineering Ltd. Wuhan, P.R. China) was $5 \mathrm{~nm}$. Transmission electron microscopy was used for detection.

\section{Statistical analysis}

Findings are presented as means and standard deviations. Group comparisons were performed using analysis of variance (ANOVA) with a Bonferroni adjustment. Data were analyzed using SAS 9.0 (SAS Institute Inc., Cary, NC, USA). All analyses were two-sided, and $p$ values of less than 0.05 were considered significant.

\section{Results}

\section{Effects of RA on the differentiation of somatotroph cells and $G H$ secretion}

First, we used immunohistochemical staining to detect the effects of RA on primary embryonic rat pituitary cell differentiation. Untreated cultures showed very few somatotroph cells (Fig. 1A). However, after RA treatment for 4 days, a number of cells changed in shape to a triangular or polygonal form and became rich in orange-staining cytoplasm, changes indicative of somatotroph cell differentiation (Fig. 1B). To determine the concentration dependence of RA-induced GH release, cells were treated with RA at different concentrations for 6 days. At a concentration $10^{-6} \mathrm{~mol} / \mathrm{L}$, but not at lower concentrations, RA significantly increased the proportion of GH positive cells (Fig. 2A) and the secretion of GH into the supernatant (Fig. 2B). ( both $P<0.01)$.

\section{Changes in the somatotroph cell differentiation after $R A$ induction over time}

Next, we investigated the effects of the duration of treatment with RA on pituitary cell differentiation. After treatment with $10^{-6} \mathrm{~mol} / \mathrm{L}$ RA for 4 days, the proportion of GH positive cells (Fig. 3A) and GH secretion 


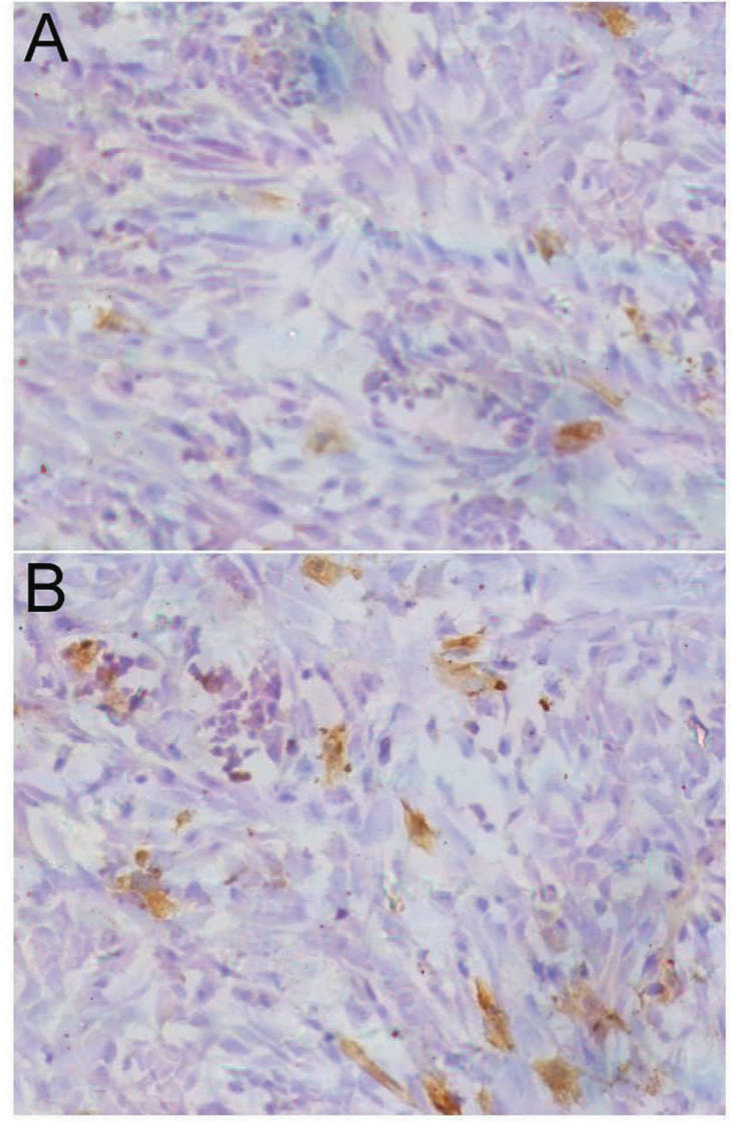

Fig. 1 Effects of retinoic acid (RA) on the differentiation of somatotroph cells by immunohistochemistry. A. When embryonic pituitary cells were maintained in DMEM alone for 4 days, few somatotroph cells were found $(\times 400)$. B. After retinoic acid (RA) treatment for 4 days, orange staining for GH is found in the cytoplasm of some cells, indicating differentiation into somatotroph cells $(\times 400)$.
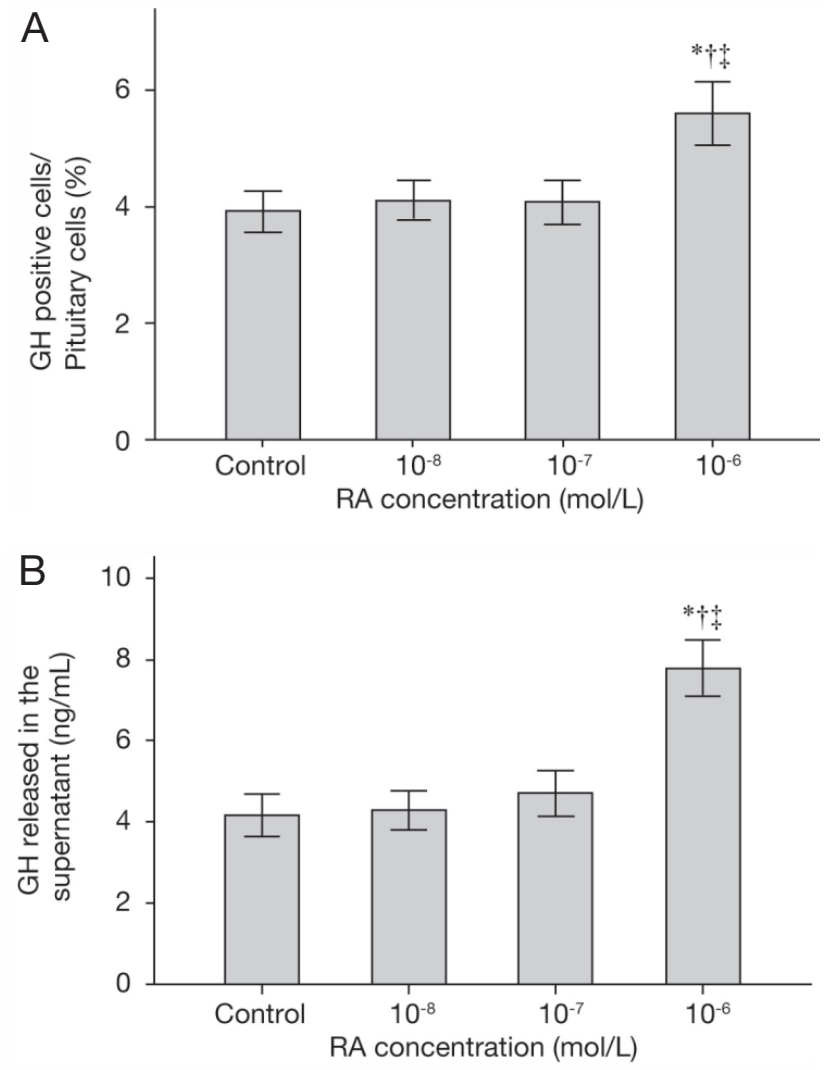

Fig. 2 Dose dependence of retinoic acid (RA) treatment on the differentiation of somatotroph cells and GH secretion. Pituitary cells were treated with different concentrations of RA $\left(10^{-8}, 10^{-7}\right.$ and $\left.10^{-6} \mathrm{~mol} / \mathrm{L}\right)$ and the percentage of GH-positive cells (A) and concentration of GH released into the supernatant (B) were assessed after 6 days of RA treatment. $* P<0.05$ compared to control, $\uparrow P<0.05$ compared to RA $\left(10^{-8} \mathrm{~mol} / \mathrm{L}\right), \ddagger P<0.05$ compared to RA $\left(10^{-7} \mathrm{~mol} / \mathrm{L}\right)$.

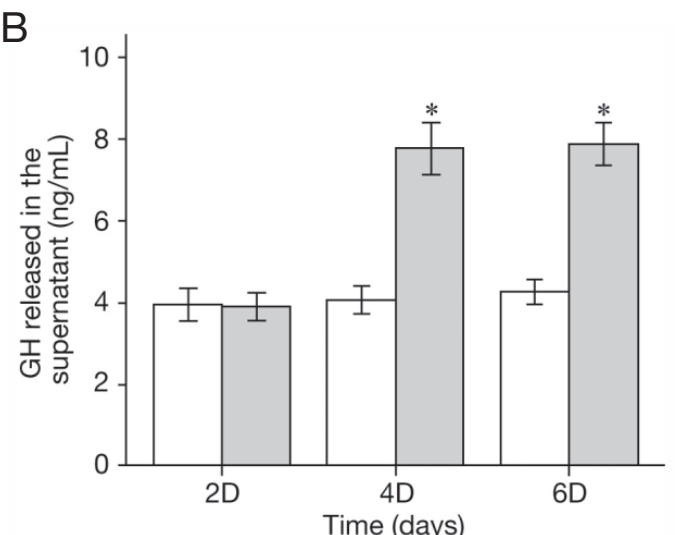

Fig. 3 Time course of changes in somatotroph cell differentiation after retinoic acid (RA) induction. Pituitary cells were treated with $10^{-6} \mathrm{~mol} / \mathrm{L}$ RA for 2, 4, or 6 days and the percentage of GH positive cells (A) and concentration of GH released in the supernatant (B) was assessed. X-axis is days of RA treatment. Blank bar is control group and gray bar is RA group. ${ }^{*} P<0.05$ compared to 2 days. 


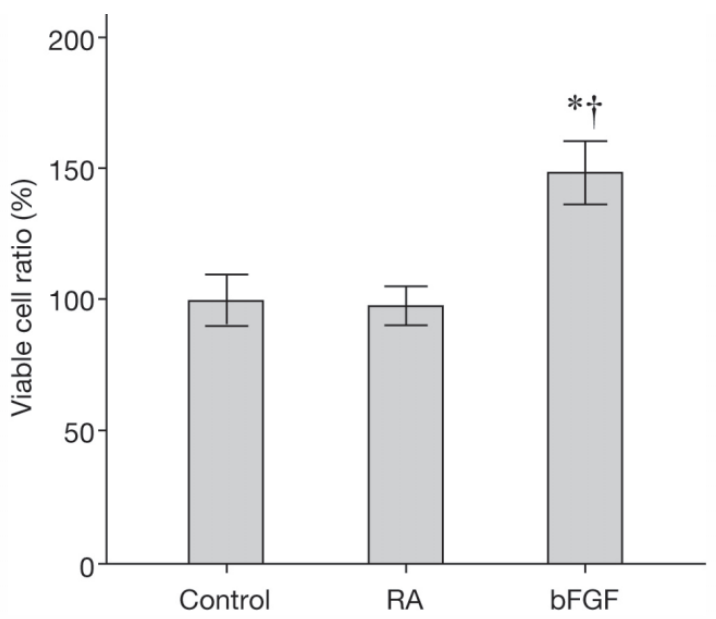

Fig. 4 The effects of retinoic acid (RA) and bFGF on the proliferation of embryonic pituitary cells. Pituitary cells were treated with $10^{-6} \mathrm{~mol} / \mathrm{L}$ RA or $10^{-6} \mathrm{~mol} / \mathrm{L} \mathrm{bFGF}$ for 4 days and the cell viability was then detected by MTT assay. $* P<0.05$ compared to control, $\uparrow P<0.05$ compared to RA treatment.

(Fig. 3B) were significantly increased compared with the no treatment control $(P<0.01)$. An additional two days of treatment with RA caused no further increase in the proportion of GH positive cells or in GH secretion ( day 4 versus day $6, P>0.05$ ).

To exclude the possibility that the effects of RA on increasing GH release and the number of GH-positive cells were due to an increase in pituitary cell number rather than an increase in differentiation of existing cells, we compared the increase in cell number after 4 days treatment with $10^{-6} \mathrm{~mol} / \mathrm{L}$ RA or $10^{-6} \mathrm{~mol} / \mathrm{L}$ bFGF. Treatment with bFGF dramatically increased the number of embryonic pituitary cells $(P<0.01)$, an effect not observed after either control or RA treatment (Fig. 4) $(P>0.05)$. Therefore, the effect of RA on these embryonic cells was on differentiation rather than proliferation.

Effects of monotreatment or combination treatment with RA, dexamethasone and GHRH on the differentiation of somatotroph cells and $G H$ secretion

The addition of dexamethasone $(50 \mathrm{nmol} / \mathrm{L})$ to $\mathrm{RA}$ $\left(10^{-6} \mathrm{~mol} / \mathrm{L}\right)$ treatment significantly increased both the proportion of somatotroph cells (Fig. 5A) and GH secretion (Fig. 5B). In contrast, the addition of GHRH to RA treatment did not increase either somatotroph proportion or GH secretion. However, the addition of GHRH to the dexamethasone-RA combination significantly increased both the proportion of somatotroph
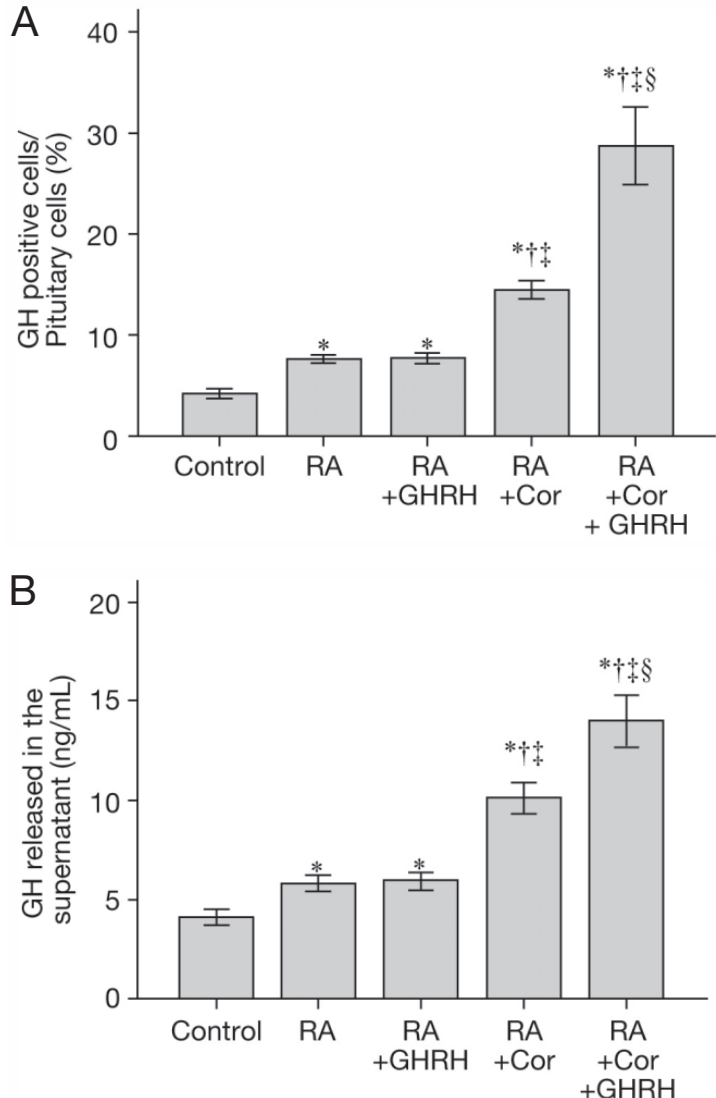

Fig. 5 Effects of monotreatment or combination treatment with retinoic acid (RA), dexamethasone (Cor) and/ or GHRH on the differentiation of somatotroph cells and GH secretion. Pituitary cells were treated with $10^{-6}$ $\mathrm{mol} / \mathrm{L}$ RA alone or in combination with dexamethasone ( $50 \mathrm{nmol} / \mathrm{L})$ and/or GHRH $\left(10^{-7} \mathrm{~mol} / \mathrm{L}\right)$ for 4 days and the percentage of GH positive cells (A) and concentration of GH released in the supernatant (B) was determined. * $P$ $<0.05$ compared to control, $\uparrow P<0.05$ compared to RA, $\ddagger P$ $<0.05$ compared to RA+GHRH, $\S P<0.05$ compared to $\mathrm{RA}+\mathrm{Cor}$

cells (28.7 $\pm 3.8 \%$ vs $7.8 \pm 0.4 \%$ or $14.5 \pm 0.9 \%)$ and GH secretion $(14.0 \pm 1.3 \mathrm{ng} / \mathrm{mL} v s 5.8 \pm 0.4 \mathrm{ng} / \mathrm{mL}$ or $10.1 \pm 0.8 \mathrm{ng} / \mathrm{mL}$ ) compared to RA treatment alone or to RA plus dexamethasone treatment (all $P<0.01$ ).

The effects of RA and dexamethasone treatment on cellular ultrastructure of pituitary cell by immune electron microscopy

When embryonic pituitary cells were obtained on E13 and treated with RA $\left(10^{-6} \mathrm{~mol} / \mathrm{L}\right)$ for 6 days, few GH positive cells were found, and these cells contained only a small number of secretory granules (Fig. 6A). After treatment with both RA $\left(10^{-6} \mathrm{~mol} / \mathrm{L}\right)$ and dexam- 

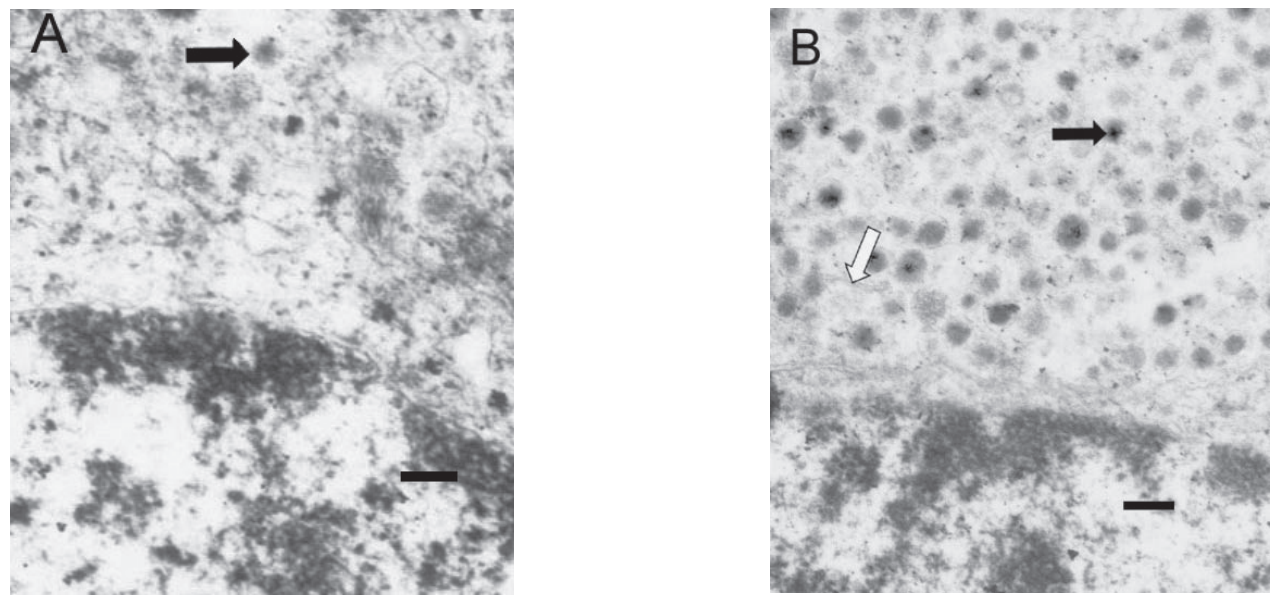

Fig. 6 Immune electron microscopy of embryonic pituitary cells after treatment with retinoic acid (RA) and/or dexamethasone. A) Somatotroph cells after treatment with RA (10-6mol/L) alone had few secretory granules (indicated by arrow). B)Somatotroph cells after treatment with RA plus dexamethasone $(50 \mathrm{nmol} / \mathrm{L})$ had an increased number of granules, with colloidal gold adherent to the granules (indicated by black arrow). Rough endoplasmic reticulum can be seen in the perinuclear area (indicated by white arrow ). The scale bar was $200 \mathrm{~nm}$.

ethasone $\left(5 \times 10^{-8} \mathrm{~mol} / \mathrm{L}\right)$, a large number of secretory granules could be observed (Fig. 6B), and colloidal gold was seen to adhere to these granules. In addition, rough endoplasmic reticulum and free ribosomes were noted in the perinuclear area.

\section{Discussion}

In the present study, primary embryonic rat pituitary cells were used to study the differentiation of somatotroph cells. Cells were maintained in serum-free medium and in this way, the influence of the maternal endocrine system and the fetal rat hypothalamus on the pituitary was avoided. Our results showed RA and dexamethasone both to be essential for the differentiation of these cells, but that these two substances acted at different stages. RA promoted early differentiation of GH cells and dexamethasone promoted both differentiation and maturation.

RA is an active metabolic product of vitamin A and plays an important role in the growth, development and cell differentiation of vertebrates, particularly during embryonic development [3]. The expression of RA and its activating enzyme, type 2 retinal dehydrogenase, in embryonic pituitary cells occurs earlier than expression of Pit-1 and GH $[4,6]$. Therefore, in the embryonic adenohypophysis, RA, when type 2 retinal dehydrogenase, is present, may promote the transcription of Pit- 1 and mRNA expression of GH, thus induc- ing early differentiation of somatotroph cells $[4,6]$.

Although the effect of RA on embryonic pituitary cells seen here was clearly on differentiation and not on proliferation, the somatotrophs induced by RA were not completely mature, because treatment with GHRH did not further increase the proportion of GH positive cells or GH secretion, and because few secretory granules seen in the GH cells after RA treatment (Fig. 6A). Therefore, as has been suggested by others $[2,4,6]$, other factors are necessary for complete functional differentiation of somatotrophs.

During embryonic development, glucocorticoids are generated by both the maternal endocrine system and the fetal adrenal gland. The glucocorticoid level in the fetus reaches a maximum at E19, at which time the number of somatotroph cells increases significantly [6]. Therefore, these changes in glucocorticoid levels are thought to play a role in somatotroph cell differentiation [6]. GH expression is maintained at a relatively low level before E19, and is dramatically increased after E19 [9].

The development of rat embryonic pituitary cells into somatotrophs can be divided into two stages. At the early stage (before E19), a certain subset of pituitary cells is targeted to become GH cells due to Pit-1 expression, but the majority of these GH cells do not or only slightly express GH. At the late stage (after E19), many of these GH precursor cells develop into GH cells having biological activity, and the produc- 
tion of GH is significantly increased [5]. Previous studies have shown that after RA treatment, additional dexamethasone treatment will markedly increase the number of GH positive cells, GH secretion, and GH mRNA expression [5]. In our study, immune electron microscopy was used to investigate the effects of combination treatment with dexamethasone and RA on the ultrastructure of somatotroph cells. After this treatment, endocrine granules in the cells were significantly increased, and the organelles were well developed (Fig. 6B). These findings suggest that dexamethasone induces the differentiation of embryonic pituitary cells into cells having biological activity and the ability to promote GH secretion.

In rats, the complex of glucocorticoids and their receptor does not directly induce the transcription of GH mRNA. The induction of GH transcription requires a second factor that is not Pit-1 [2]. One possibility is that glucocorticoids induce a factor that acts on the ciselement in the promoter or enhancer region of the GH gene, or that it changes local chromatin structure in a way that enhances GH transcription. Another possibility is that glucocorticoids can induce expression of a factor that abolishes the suppression of GH expression by other factors. Currently, nandrolone phenylpropionate, insulin and insulin-like growth factor can inhibit the $\mathrm{GH}$ expression in the pituitary $[10,11]$. Perhaps before E19, one or more of these substances suppresses GH expression, and this suppression can be counteracted by glucocorticoids through inducing a factor resulting in increased GH expression.

GHRH plays a role in GH cell proliferation and GH synthesis as well as causing GH secretion [12]. During the embryonic development of the rat hypothalamicpituitary axis, GHRH-producing neurons in the hypothalamus develop at an earlier time than GH-producing cells in the pituitary. At E16, expression of GHRH mRNA is detectable in the arcuate nucleus. On the E18, some nerve terminals expressing GHRH are seen to project to the median eminence. In addition, the vascular connection between the hypothalamus and anterior pituitary is also present [13]. This anatomical evidence shows that GHRH may be able to regulate somatotroph function after day E18. But GHRH is able to cause GH secretion only after its receptor is detectable, an event that occurs after E19 [13]. Only when GHRH is bound to GHRH-R can it initiate the
cAMP and $\mathrm{Ca}^{2+}$ cascade responsible for its physiological function [14].

In the present study, GHRH, when given alone on day 4 of RA treatment, did not increase the proportion of GH positive cells or GH secretion. However, when glucocorticoids were added at the same time as GHRH, a significant increase of GH-positive cells and GH secretion did occur $(P<0.01)$. Activation of GHRH-R transcription by glucocorticoids could explain this result. Therefore, the synergism between GHRH and glucocorticoids may be related to glucocorticoid induction of increased GHRH-R mRNA expression and a resulting increase in GHRH binding sites on somatotrophs. Furthermore, glucocorticoids can also promote the secretion of GH by GHRH [15]. These findings also show that differentiated somatotroph cells after in vitro induction respond to GHRH.

A limitation of the study is that we did not count and compare actual numbers, either of viable cells or secretory granules, but used other techniques to demonstrate differences between treatments.

At present, for transplantation of pituitary cells to succeed, it is critical to acquire enough cells to meet the transplantation requirements of individual patients. Our study is the first to use mammalian primary cell culture, instead of explants or cell lines, to study the effect of RA, dexamethasone, and GHRH on somatotroph differentiation. The embryonic pituitary cells obtained were maintained in serum free medium, and used to mimic the different stages of differentiation into somatotroph cells. Our results showed RA and glucocorticoids to play sequential roles in somatotroph differentiation, and GHRH and glucocorticoids to exert synergistic effects in promoting the differentiation and proliferation of somatotroph cells. In addition, an optimal protocol was established for the in vitro induction of somatotroph cell differentiation that may provide a future basis for the selective somatotroph cell growth and transplantation in the treatment of GH deficiency.

\section{Acknowledgements}

This study was supported by the Natural Science Foundation of Heilongjiang Province (No. D2007-12), Heilongjiang Province Health Department Issues (No. 2007-284). 


\section{References}

1. Scully KM, Rosenfeld MG (2002) Pituitary development: regulatory codes in mammalian organogenesis. Science 295: 2231-2235.

2. Nogami H, Inoue K, Kawamura K (1997) Involvement of glucocorticoid-induced factor(s) in the stimulation of growth hormone expression in the fetal rat pituitary gland in vitro. Endocrinology 138: 1810-1815.

3. Campo-Paysaa F, Marlétaz F, Laudet V, Schubert M (2008) Retinoic acid signaling in development: tissuespecific functions and evolutionary origins. Genesis 46: 640-656.

4. Mogi C, Goda H, Mogi K, Takaki A, Yokoyama K, Tomida M, Inoue K (2005) Multistep differentiation of GH-producing cells from their immature cells. $J$ Endocrinol 184: 41-50.

5. Nogami H, Matsubara M, Harigaya T, Katayama M, Kawamura K (2000) Retinoic acids and thyroid hormone act synergistically with dexamethasone to increase growth hormone-releasing hormone receptor messenger ribonucleic acid expression. Endocrinology 141: 43964401.

6. Nogami H, Hisano S (2008) Functional maturation of growth hormone cells in the anterior pituitary gland of the fetus. Growth Horm IGF Res 18: 379-388.

7. Krylyshkina O, Chen JH, Mebis L, et al. (2005) Nestin-Immunoreactive Cells in Rat Pituitary Are neither Hormonal nor Typical Folliculo-Stellate Cells. Endocrinology 146: 2376-2387.

8. Hauspie A, Seuntjens E, Vankelecom H, Denef C. (2003) Stimulation of combina-torial expression of prolactin and glycoprotein hormone alpha-subunit genes by gonadotropin-releasing hormone and estradiol-17beta in single rat pituitary cells during aggregate cell culture. Endocrinology 144: 388-399.

9. Manojlović-Stojanoski M, Nestorović N, Negić N, Filipovic B, Sosic-Jurjevic B, Sekulic M, Milosevic $\mathrm{V}$ (2007) Influence of maternal dexamethasone treatment on morphometric characteristics of pituitary GH cells and body weight in near-term rat fetuses. Folia Histochem Cytobiol 45: 51-56.

10. Childs GV, Unabia G, Wu P (2000) Differential expression of growth hormone messenger ribonucleic acid by somatotropes and gonadotropes in male and cycling female rats [J]. Endocrinology 141: 1560-1570.

11. Voss TC, Flynn MP, Hurley DL (2001) IGF-I causes an ultrasensitive reduction in GH mRNA levels via an extracellular mechanism. Mol Endocrinol 5: 549-558.

12. Mayo KE, Miller T, DeAlmeida V, Godfrey P, Zheng J, Cunha SR (2000) Regulation of the pituitary somatotroph cell by GHRH and its receptor [J]. Recent Prog Horm Res55: 237-267.

13. Nogami H, Inoue K, Moriya H (1999) Regulation of growth hormone-releasing hormone receptor messenger ribonucleic acid expression by glucocorticoids in MtT-S cells and in the pituitary gland of fetal rats. Endocrinology 140: 2763-2770.

14. Miller TL, Godfrey PA, Dealmeida VI, Mayo KE (1999) The rat growth hormone-releasing hormone receptor gene: structure, regulation, and generation of receptor isoforms with different signaling properties. Endocrinology 140: 4152-4165.

15. Dean CE, Porter TE (1999) Regulation of somatotroph differentiation and growth hormone (GH) secretion by corticosterone and GH-releasing hormone during embryonic development. Endocrinology 140: 11041110. 